\title{
Do smoking ordinances protect non-smokers from environmental tobacco smoke at work?
}

\author{
John P Pierce, Thomas G Shanks, Mark Pertschuk, Elizabeth Gilpin, \\ Donald Shopland, Michael Johnson, Dileep Bal
}

\begin{abstract}
Objective - To establish the relationship between the existence and extent of local smoking ordinances pertaining to the workplace and non-smoker exposure to environmental tobacco smoke (ETS).

Design - Telephone survey.

Subjects-Population-based sample of California residents $\geqslant 18$ years of age $(n=12802)$ interviewed as part of the 1990-91 California Tobacco Survey.

Main outcome measures - Local smoking ordinances, ETS exposure, workplace smoking policies.

Results - Overall， $40.6 \pm 1.6 \% \quad( \pm 95 \%$ confidence interval) of California indoor workers worked in areas with strong local smoking ordinances, $31.9 \pm 1.7 \%$ in areas with weak ordinances, and $27.6 \pm 1.5 \%$ in areas with no local ordinances. Nonsmoker exposure to ETS ranged from $24.5 \pm 1.9 \%$ for those working in areas with a strong ordinance to $34.8 \pm 3.2 \%$ for those working where no ordinance was in effect $\left(p<10^{-4}\right)$. The percentage of indoor workers working in a smoke-free workplace decreased from $40.3 \pm 1.7 \%$ for those covered by a strong ordinance to $31.1 \pm 2.4 \%$ where there was no ordinance $\left(p<10^{-5}\right)$. However, in 1990 , about $40 \%$ of indoor workers who worked in areas with a strong ordinance reported that their workplace had either no policy or only a weak policy restricting smoking.

Conclusions-Strong smoking ordinances play an important role in reducing non-smoker exposure to ETS because the ordinances increase the likelihood that workplaces have anti-smoking policies. However, ordinances have yet to reach their full potential in protecting the nonsmoker from ETS due to lack of employer compliance.
\end{abstract}

(Tobacco Control 1994; 3: 15-20)

\section{Introduction}

The health effects of environmental tobacco smoke (ETS) to the non-smoker include an increased risk of lung cancer and heart disease as well as a range of respiratory illnesses..$^{1-3}$ In addition to disease, many employees have reported discomfort from ETS in workplaces that permit smoking even if only in designated areas. ${ }^{4}$ Non-smoker exposure to someone smoking recently in their work area (our measure of ETS exposure) is strongly related to the existence and extent of workplace smoking policies, with the lowest levels of exposure occurring in smoke-free workplaces. ${ }^{5}$ Compared to non-smokers working in smokefree worksites, ETS exposure was increased by a factor of 2.5 when the worksite smoking policy covered the work area but was not a total ban; with no policy or only a token policy, ETS exposure was more than eight times as high. ${ }^{5}$

Early workplace smoking policies were implemented primarily for safety reasons, but the majority of recent policies have been adopted to protect workers from ETS or to comply with smoking ordinances. Surveys of businesses suggest that many wait until they are legally required to restrict smoking before implementing a specific policy to protect non-smoking employees. ${ }^{2}$

Through the use of ordinances, local governments have the power to mandate that nonsmokers be protected from ETS in industries that employ workers or service the public within the local government area. It has been reported recently that laws restricting smoking increased considerably at the local level throughout the 1980 s so that by July 1989,44 or 45 states reported some legal restriction on smoking. ${ }^{6,7}$ However, comprehensive laws requiring smoke-free workplaces were uncommon in the US in $1989 .^{6,8}$ Between 1989 and 1992 the number of smoke-free workplace ordinances increased considerably. ${ }^{9}$

In this paper, we report population-based estimates of the percentages of California indoor workers covered by local smoking ordinances in 1990 and 1991. Further, we describe the association between the strength of these ordinances and the existence of worksite smoking policies and the exposure of non-smoking indoor workers to ETS.

\section{Methods}

SURVEY METHODS AND RESPONSE RATES

Between June 1990 and July 1991, 26815 adults were interviewed as part of the California Tobacco Surveys (CTS) commissioned by the California Department of Health Services and the Los Angeles Department of Health Services to establish a baseline for the evaluation of the California Tobacco Tax Initiative. Fieldwork for these surveys was undertaken by Westat, Inc, using a stratified Waksberg random-digit-dial telephone meth- 
odology..$^{10}$ Information on the smoking status of all household members was obtained from 57246 households in California (response rate $=75.1 \%$ ). An extended interview was conducted with 26815 adults: for the statewide survey, this group included $28 \%$ of all adult non-smokers, as well as all adults who had smoked in the last 5 years; for the Los Angeles supplementary survey, all Asian adults (2519) were scheduled for an extended interview. The response rate for the combined extended interview was $78 \%$.

The survey was designed to be representative of 18 geographic regions of California, 10 of which represented the most populous counties: Los Angles, San Diego, Orange, Santa Clara, San Bernardino, Alameda, Riverside, Sacramento, Contra Costa, and San Francisco. The remaining 48 counties were allocated (in consultation with the counties themselves) into eight regions, containing between two and 15 counties each, designed to be somewhat similar and to have base populations of no less than 400000 people. Poststratification weighting ensured that the regional samples were representative of the 1990 census data by age, sex, education level, and race/ethnicity.

Of the adults surveyed, 13199 indicated that they worked primarily indoors. The indoor workers were asked for the location of their workplace by postal ZIP code or town name. This information was used to determine the geographic location of the workplace for 12802 $(96.5 \%)$ of the respondents. The location was then related (see below) to the level of the smoking ordinance in effect at that location during 1990, the period of the survey.

The 14-minute (average time) extended interview included a complete recent and lifetime smoking history and current and past use of other tobacco products. The survey also asked questions concerning health beliefs, social attitudes, policy-related opinions, smoking restrictions encountered in the workplace, physician advice to stop smoking, non-smoker assertiveness, and exposure to media messages regarding smoking.

\section{QUESTIONS ANALYSED}

Workplace restrictions on smoking were ascertained from three questions. First, "Do you/ Does your employer have an official policy that restricts smoking in any way?" Those who answered "yes" were asked two follow-up questions: "Which of the following best describes the smoking policy for indoor public or common areas such as lobbies, restrooms and lunchrooms?" and "Which of the following best describes the policy for areas in which employees work?" Response choices were: not allowed in any, allowed in some, or allowed in all. From the responses to these questions, workplaces were categorised into the following three groups: 1) smoke-free workplace: smoking banned completely in both public and common areas and in work areas, 2) work area ban only: smoking allowed in some or all public or common areas but banned in work areas, 3) lesser or no restrictions: allowed in work area but some restrictions on public or common areas or no restrictions at all. Only $2.7 \%$ of respondents did not provide sufficient information to allow classification of workplace smoking restrictions. Respondents were also asked, "Altogether, do more than 50 people work at your worksite?" Exposure to ETS at work was assessed from the question, "During the past two weeks has anyone smoked in the area in which you work?"

Smoking status was assessed according to the standard questions, ${ }^{2,11}$ "Have you smoked at least 100 cigarettes in your entire life?" and "Do you smoke cigarettes now?" Those responding "yes" to both questions were considered current smokers, those responding "yes" to the first question and "no" to the second one were considered former smokers, and the remainder were considered neversmokers. Both former and never-smokers were considered non-smokers for the analysis of ETS exposure.

Two additional questions were examined as a measure of non-smoker assertiveness: "In the past 12 months have you ever asked someone not to smoke in a certain situation?", and, if the answer to this question was "no", respondents were asked: "Would you ever ask someone not to smoke?"

DEFINITION OF WORKPLACE ORDINANCE LEVELS Smoking ordinances vary primarily in two ways: comprehensiveness and strength. A comprehensive ordinance covers workplaces, restaurants, and other enclosed public places, such as retail stores. An ordinance that covers only restaurants, for example, is not considered comprehensive. The strength of the ordinance relates to whether the requirement is for no smoking at all or for more limited restrictions. The strength of smoking ordinances varies widely, with more recently adopted laws tending to be stronger.

In this study, we were concerned with the local laws regulating smoking in the workplace. The questionnaire asked each respondent for his or her workplace ZIP code (provided by $77.4 \%$ of respondents), and if the ZIP code was not known, another question asked for the town name (provided by another $19.1 \%$ of respondents). We then used a database maintained by Americans for Nonsmokers' Rights (Berkeley, California) under the auspices of the National Cancer Institute to classify the strength (strong, weak, or nonexistent) of the ordinance for each location as of June 1990. The primary criterion for the existence of an ordinance was inclusion of some provision protecting employees in both the private and public sectors from ETS. For a local ordinance to be classified as strong, it had to have a "nonsmoker preference clause" (giving the nonsmoker's need for smoke-free air priority in conflict regarding the smoking policy) or a clause permitting non-smokers to designate their own immediate work areas as nonsmoking, and it had to prohibit smoking in 
common areas such as meeting rooms, halls and restrooms. All other workplace ordinances were classified as weak. According to these criteria, ordinances regulating smoking only in local government buildings were not judged to qualify as weak ordinances and were grouped in the nonexistent category.

These designations were then checked with a separate classification system developed by San Diego State University from responses by individual counties to questions on the ordinances in existence in 1990. Finally, the resultant classification of ordinances for areas within each county was verified by the county Tobacco Control Program Coordinator. Any remaining discrepancies were resolved by reviewing the actual text of the ordinance in effect at the time of the survey. Minor modifications were made following each verification step. Although the survey continued into mid-1991 in Los Angeles County, no changes in smoking ordinances occurred there during this period.

\section{STATISTICS}

Confidence intervals for all percentages reported were derived by a variant of the jackknife procedure. ${ }^{12}$ In this study, 33 subsamples were taken from the full survey file, and sample weights were computed according to the same procedure used for the full sample. Variances were estimated based on the deviations of the subsample percentages from those of the full sample. The computed variances were then used to derive $95 \%$ confidence intervals in the usual manner. Chi-square statistics were computed using a method (Satterthwaite's approximation) based on the subsamples (see above) which adjusts for survey design. ${ }^{13}$ Pearson's simple and partial correlation coefficients were computed to examine the relationships among non-smoker ETS exposure, level of worksite smoking policy, and level of local ordinances among the 18 California regions.

\section{Results}

SMOKING ORDINANCES IN CALIFORNIA IN 1990 In 1990, approximately 190 local smoking ordinances existed in California. Of these, approximately 175 contained provisions limiting smoking in workplaces. Of the 13199 indoor workers interviewed in the CTS, we were able to classify 6184 subjects $(39.1 \pm$ $1.6 \%$ ) as working in areas with strong ordinances; $3121(30.7 \pm 1.6 \%)$ as working in areas with weak ordinances; and $3497(26.6 \pm 1.5 \%)$ as working in areas with no ordinances. Some $397(3.5 \%)$ respondents could not be matched with an ordinance because the town name could not be identified or was out of state; these workers were not included in the analyses described below.

Of those indoor workers whose workplace could be categorised, $40.6 \pm 1.6 \%$ were covered by strong smoking ordinances, $31.9 \pm 1.7 \%$ by weak ordinances, and $27.6 \pm 1.5 \%$ by no ordinance. A high percentage of workers residing in Alameda, Contra Costa, Santa Clara, San Francisco, and Sacramento counties were covered by strong ordinances whereas workers in San Diego, Los Angeles, and the region comprising San Luis Obispo, Santa Barbara, and Ventura counties predominantly worked under weak ordinances. The highest percentages of workers not covered by a smoking ordinance were in the region including Imperial, Inyo, Kern, Kings, Mono, and Tulare counties; in the region including Butte, Colusa, Del Norte, Glenn, Humbolt, Lake, Lassen, Mendocino, Modoc, Plumas, Shasta, Siskiyou, Tehama, Trinity, and Yolo counties; and in Orange and San Bernardino counties.

ORDINANCE LEVEL AND THE TYPE OF WORKSITE SMOKING POLICY

Worksites in areas with strong ordinances were more likely to have total smoking bans than those with weak or no ordinances (figure 1). The percentage of indoor workers covered by a total ban decreased from $40.3 \pm 1.7 \%$ for those in locations with strong ordinances to $36.0 \pm 2.6 \%$ for those in locations with weak ordinances, and to $31.1 \pm 2.4 \%$ for those not covered by a smoking ordinance. These differences are statistically significant $\left(\mathrm{p}<10^{-5}\right)$. Conversely, the percentage of workers covered by lesser or no worksite smoking restrictions at all increased as the ordinance level declined from strong to no ordinances.

ORDINANCE LEVEL, WORKSITE POLICY, AND ETS EXPOSURE

Figure 2 provides the percentages of nonsmokers $(n=8501)$ exposed to ETS in work-

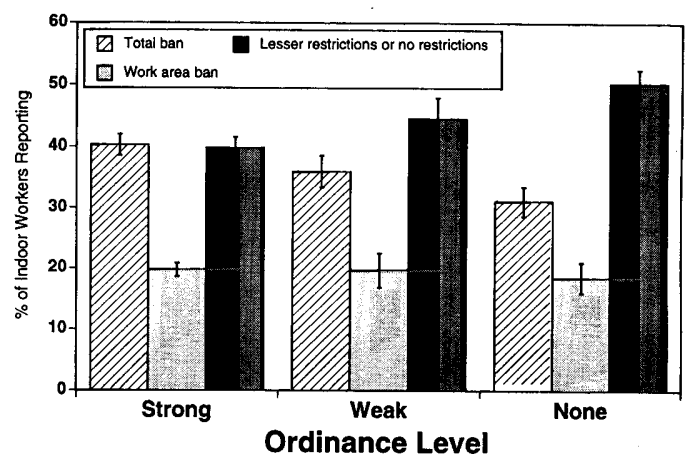

Figure 1 Worksite smoking policy according to level of ordinance.

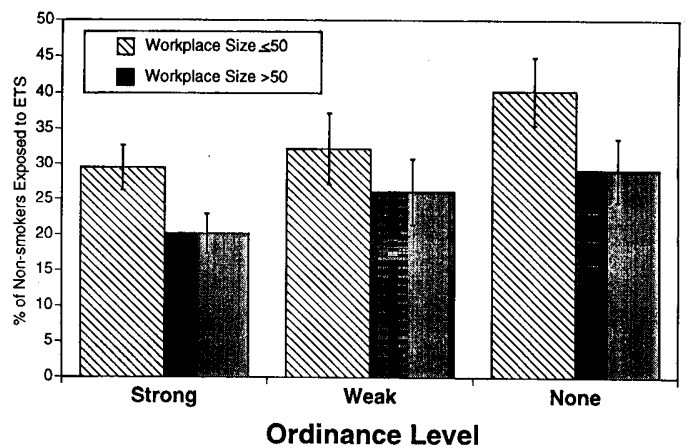

Figure 2 Exposure of non-smokers to ETS by ordinance level and size of workplace. 
sites by strength of ordinance and workplace size. Non-smoker exposure to ETS appears to be lower in larger workplaces compared to smaller workplaces regardless of the strength of ordinance in effect $(24.3 \pm 2.4 \%$ vs $33.4 \pm$ $1.8 \%$, respectively, $\left.\mathrm{p}<10^{-6}\right)$. Non-smokers were evenly distributed between small and large workplaces. In strong ordinance areas (regardless of workplace size) the overall percentage of non-smokers exposed to ETS was $24.5 \pm 1.9 \%$; in weak ordinance areas exposure was $29.1 \pm 3.8 \%$; and in no ordinance areas it was $34.8 \pm 3.2 \%\left(\mathrm{p}<10^{-4}\right)$.

Figure 3 shows the percentage of nonsmokers exposed to ETS in worksites with a total ban, work area ban, and lesser or no restrictions, according to whether the workplace was in an area with strong, weak, or no ordinances. This figure shows that the level of ETS exposure is more strongly related to the strength of the worksite smoking policy than to the existence of an ordinance. Even in areas with no ordinance, exposure to ETS is low if the workplace is smoke-free. However, in worksites with a work area ban, but not a total ban, the existence of a strong ordinance appears to reduce the exposure to non-smokers to ETS $(14.4 \pm 3.1 \%)$, compared to areas with weak $(28.1 \pm 9.4 \%)$ or no ordinances $(26.5 \pm$ $6.6 \%)(\mathrm{p}<0.012$ with work area ban category; $\mathrm{p}<10^{-6}$ overall).

The correlation between the rate of ETS exposure of non-smokers and the rate of smoke-free workplaces among the 18 regions was high $\left(\mathrm{r}=-0.84, \mathrm{p}<10^{-4}\right.$, two-sided). Regions with workers reporting the highest percentages of smoke-free workplaces had the lowest levels of non-smoker ETS exposure. The relationship between ETS exposure rates for non-smokers and the rates of coverage by strong ordinances was lower but still significant $(\mathrm{r}=-0.48, \mathrm{p}<0.05$, two-sided $)$. When a partial correlation coefficient was computed between the rate of non-smoker ETS exposure and the prevalence of strong ordinance controlling for the rate of smokefree worksites, the correlation was only marginally altered ( $\mathrm{r}=-0.52, \mathrm{p}<0.05$, two-sided).

\section{RELATIONSHIP OF ORDINANCE LEVEL AND RESPONDENT SMOKING STATUS AND ASSERTIVENESS}

One might hypothesise that the existence or strength of an ordinance is related to smoking prevalence in the local area or to the degree of non-smoker assertiveness in the local area. However, figure 4 shows that the percentage of smokers in areas classified as having strong, weak, or no ordinances is remarkably uniform $(\mathrm{p}<0.11)$.

The degree of non-smoker assertiveness, as measured by reported willingness to ask someone not to smoke, also appears to be unrelated to the existence or strength of a local area ordinance (table). The percentage of nonsmokers who have recently asked someone not to smoke or who would be willing to ask does not differ significantly among the ordinance groups.

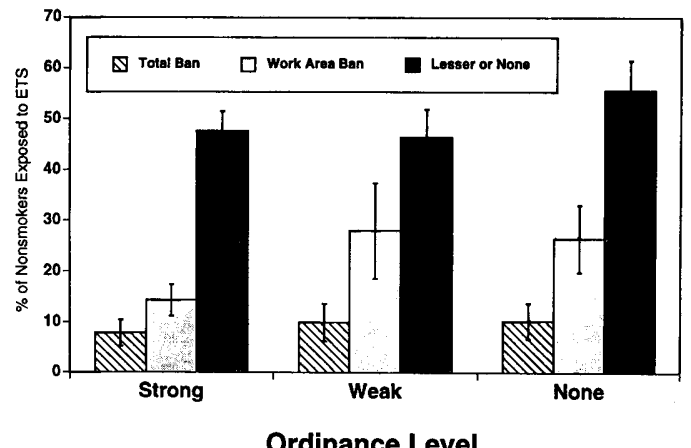

Figure 3 ETS exposure of non-smokers by worksite smoking policy and ordinance level.

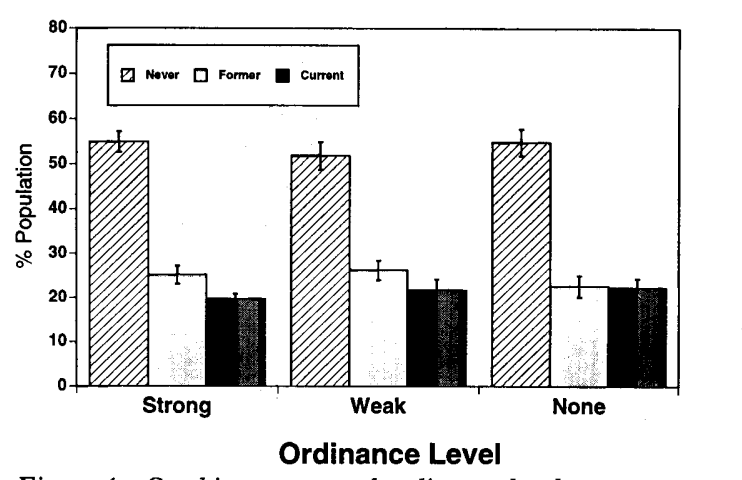

Figure 4 Smoking status and ordinance level.

Table Ordinance level related to non-smoker antismoking assertiveness

\begin{tabular}{lccc}
\hline & \multicolumn{3}{c}{ Ordinance level } \\
\cline { 2 - 4 } & $\%$ strong & $\%$ weak & $\%$ none \\
\hline Recently asked & $48.4 \pm 2.4$ & $44.0 \pm 4.8$ & $45.6 \pm 5.1$ \\
Has, but not recently & $29.9 \pm 1.9$ & $33.3 \pm 5.3$ & $30.3 \pm 5.2$ \\
Not willing to ask & $21.8 \pm 2.2$ & $22.7 \pm 3.8$ & $24.1 \pm 4.2$ \\
\hline
\end{tabular}

Entries are weighted percentages $\pm 95 \%$ confidence intervals.

\section{Discussion}

We have shown previously that the level of worksite smoking policy is highly related to non-smokers reporting ETS exposure in their work area. ${ }^{5}$ The current report establishes for the first time that strong local area smoking ordinances increase the likelihood that worksites have smoke-free policies. The variability among the 18 regions in California further demonstrates the relationship between increased non-smoker protection from ETS and the existence of strong smoking ordinances. Even when controlling for the percentage of non-smokers covered by smoke-free workplaces, the relationship between strong ordinances and non-smoker ETS exposure was apparent. To our knowledge, the results from this study provide the first link between the existence of smoking ordinances and protection of non-smokers from ETS.

In addition to protecting the non-smoker from ETS, strong worksite smoking policies appear to reduce cigarette consumption by regular smokers, ${ }^{14-17}$ and to encourage quitting. ${ }^{15,18-20}$ It also has been suggested that restrictive smoking policies may discourage young people from starting to smoke. ${ }^{14,15,21-24}$ In another analysis of the CTS data, we 
projected that cigarette consumption would drop by about $40 \%$ among indoor workers if all worksites were smoke-free. ${ }^{17}$ Thus, to the extent that smoking ordinances promote the adoption of meaningful worksite smoking policies, they produce health benefits for smokers as well.

Tobacco companies have lobbied relentlessly to dilute and delay the passage of protective legislation. However, in a case study of the consideration of three such ordinances by local governments in California in 1990, Samuels and Glantz concluded that the prohealth lobby at the local community level also had considerable power to influence the passage of such ordinances. ${ }^{25}$ Indeed, they concluded that if the pro-health lobby mobilised its resources effectively, it would be able to overcome the influence of tobacco companies and ensure that protective ordinances are passed and not repealed. Our measure of personal assertiveness (table) was not related to an increased prevalence of smoking ordinances. However, the level of motivation to act as an individual is different from the level of motivation that would lead someone to join an organisation that works for non-smokers' rights. Also, we could not demonstrate any link between smoking prevalence and the existence of smoking ordinances.

In areas with strong local ordinances, work area smoking bans (a less restrictive category than a total ban) appear to be substantially more effective in reducing non-smoker exposure to ETS (figure 3). One possible explanation for this finding is the right of the non-smoker covered by a strong ordinance to dictate workplace policy in the event of a conflict between a smoker and a non-smoker. Furthermore, strong ordinances provide legal recourse for any individual dismissed from a job for asserting the right to a non-smoking working environment. Another possible explanation is that in some areas community norms, which possibly led to the passage of strong smoking ordinances, may have an impact. Perhaps non-smokers are more assertive or smokers more sensitive regarding smoking where work area restrictions are in place.

Smoking ordinances can only be effective in protecting non-smokers from ETS if their provisions are actually implemented in the workplace. About $40 \%$ of the workers in our survey who worked in areas with strong ordinances reported minimal or no smoking restrictions in their workplace (figure 1). This finding may reflect either a lack of knowledge on the part of the employees concerning existing smoking policies or the need for increased compliance with local ordinances. Typically, smoking ordinances are enforced by public health departments with little or no resources allocated for this effort. ${ }^{2}$ Ordinances are enforced only in response to complaints. ${ }^{8}$

In January 1993 the US Environmental Protection Agency issued a report classifying ETS as a Group A (known human) carcinogen on a par with asbestos. ${ }^{26}$ Already, employers have been sued by workers who developed smoking-related diseases after long-term exposure to ETS at their workplace. ${ }^{9,27,28} \mathrm{Com}-$ pliance with local smoking ordinances will probably increase when the legal implications about employer liability become more well known. Also, local governments that have only weak or no ordinances will probably enact stronger and more comprehensive ones. For instance, some ordinances apply only to larger businesses, and this, together with difficulty in providing separate smoking areas in small firms, may account for the difference in nonsmoker ETS exposure with worksite size (figure 2). Strong ordinances that require smoke-free workplaces simplify the issue of compliance within a workplace, because there is no interpretation of where smoking is or is not allowed. Encouragingly, the number of smoke-free ordinances passed in the US has increased dramatically from fewer than five in 1990 to over 30 in $1992 .^{9}$

In conclusion, strong smoking ordinances are effective in reducing ETS exposure and appear to strengthen the effectiveness of work area bans in protecting non-smokers from ETS. Those interested in encouraging compliance with existing ordinances or promoting the adoption of stronger and more comprehensive ordinances should keep abreast of the legal implications of ETS being classified as a Group A carcinogen and use this information to lobby convincingly for these actions at the local level.

This study was supported by Contract \#89-97872 from the California Department of Health Services, Tobacco Control Section, and Contract \# 64182 from the County of Los Angeles Tobacco Control Section.

1 National Research Council. Environmental tobacco smoke: measures of exposure and assessing health effects. Washington, DC: National Academy Press, 1986.

2 US Department of Health and Human Services. Reducing the health consequences of smoking: 25 years of progress. $A$ report of the Surgeon General, 1989. Atlanta, Georgia: Office on Smoking and Health, Centers for Disease Control, 1989. (DHHS Publication No (CDC) 89-8411.)

3 Glantz SA, Parmley WW. Passive smoking and heart disease: epidemiology, physiology, and biochemistry. Circulation 1991; 83: 1-12.

4 US Centers for Disease Control. Discomfort from environmental tobacco smoke among employees at worksites with minimal smoking restrictions - United States, 1988. $M M W R$ 1992; 41: 351-4.

5 Borland R, Pierce JP, Burns DM, Gilpin E, Johnson M, Bal $D$. Protection from environmental tobacco smoke. The case for a smoke-free workplace. $\mathfrak{F A M A} 1992 ; 268$ : 749-52.

6 Rigotti NA, Pashos CL. No-smoking laws in the United States. An analysis of state and city actions to limit smoking in public places and workplaces. $\mathscr{F} A M A 1991$; 266: 3162-7.

7 US Centers for Disease Control. State tobacco prevention and control activities: results of the 1989-1990 Association of State and Territorial Health Officials (ASTHO) Survey-Final report. $M M W R$ 1991; 40 (No. RR-11), p. 4.

8 Pertschuk M, Shopland DR, eds. Major local smoking ordinances in the United States. A detailed matrix of the provisions of workplace, restaurant and public places smoking ordinances. US Department of places Human Services, Public Health Service, $\mathrm{Health}$ and Human Services, Public Health Service, National Institutes of Health, National Cancer

9 Pertschuk M, Shopland DR, eds. Major local tobacco control ordinances in the United States. US Department of Health and Human Services, Public Health Service, National Institutes of Health, National Cancer Institute, 1993. (DHHS Publication No (NIH) 93-3532.)

10 Waksberg J. Sampling methods for random digit dialing. $f$ Am Stat Assoc 1978; 73 (361): 40-6.

11 US Department of Health and Human Services. Smoking, tobacco and cancer program: 1985 Report. Bethesda Maryland: National Institutes of Health, 1986. (DHHS Publication (NIH) 86-2687.)

12 Efron B. The jackknife, the bootstrap and other resampling 
plans. CBMS Regional Conference Series in Applied Mathematics, 38. Philadelphia, PA: Society for Industria and Applied Mathematics, 1982.

13 Rao JNK, Scott AJ. The analysis of categorical data from complex sample surveys: chi-square tests for goodness of fit and independence in two-way tables. $\mathcal{F}$ Am Stat Assoc 1981; 76: 221-30.

14 Borland R, Chapman S, Owen N, Hill D. Effects of workplace smoking bans on cigarette consumption. $A m \tilde{F}$ 列

15 Stillman FA, Becker DM, Swank RT, Hantula D, Moses $\mathrm{H}$, Glantz S. Ending smoking at the Johns Hopkins Medical Institutions: an evaluation of smoking preva lence and indoor air pollution. $\mathcal{f} A M A$ 1990; 264:1565-9.

16 Biener L, Abrams DB, Follick MJ, Dean L. A comparative evaluation of a restrictive smoking policy in a general hospital. Am F Public Health 1989; 79: 192-5.

17 Woodruff TJ, Rosbrook B, Pierce J, Glantz SA. Lower levels of cigarette consumption found in smoke-free workplaces in California. Arch Intern Med 1993; 153: 1485-93.

18 Borland R, Owen N, Hill D, Chapman S. Changes in acceptance of workplace smoking bans following their implementation: a prospective study. Prev Med 1990;19: 314-22.

19 Sorensen G, Rigotti N, Rosen A, Pinney J, Prible R. Effects of a worksite nonsmoking policy: Evidence for increased cessation. Am ₹ Public Health 1991; 81: 202-4.

20 Hudzinski LG, Frohlich ED. One-year longitudinal study of a no-smoking policy in a medical institution. Chest 1990; 97: 1198-202.

21 Millar WJ. Evaluation of the impact of smoking restrictions in a government work setting. Can f Public Health 1988 79: 379-82.

22 Petersen LR, Helgerson SD, Gibbons CM, Calhoun CR Ciacco KH, Pitchford KC. Employee smoking behaviour changes and attitudes following a restrictive policy on
worksite smoking in a large company. Public Health Rep worksite smoking in

23 Hill D, Borland R. Adults' accounts of onset of regular smoking. Influences of school, work, and other settings. Public Health Rep 1991; 106 : 181-5.

24 Pierce JP, Naquin M, Gilpin E, Giovino G, Mills S Marcus S. Smoking initiation in the United States: a role for worksite and college smoking bans. $\mathcal{f}$ Natl Cancer Inst $1991 ; 83: 1009-13$

25 Samuels B, Glantz SA. The politics of local tobacco control. FAMA 1991; 266: 2110-7.

26 US Environmental Protection Agency. Respiratory health effects of passive smoking : lung cancer and other disorders. Washington, DC: Office of Research and Development and Office of Air and Radiation, 1992. (Publication no EPA $/ 600 / 6-90-006 \mathrm{~F}$.

27 Ubbi $v$ State Compensation Insurance Fund (Cat ' $n$ ' Fiddle Restaurant), No SFO-0341691, California Workers' Compensation Appeals Board (1990).

28 Fernandez E. Study says smoky air endangers waitresses. San Francisco Chronicle. October 23, 1992: A-1.

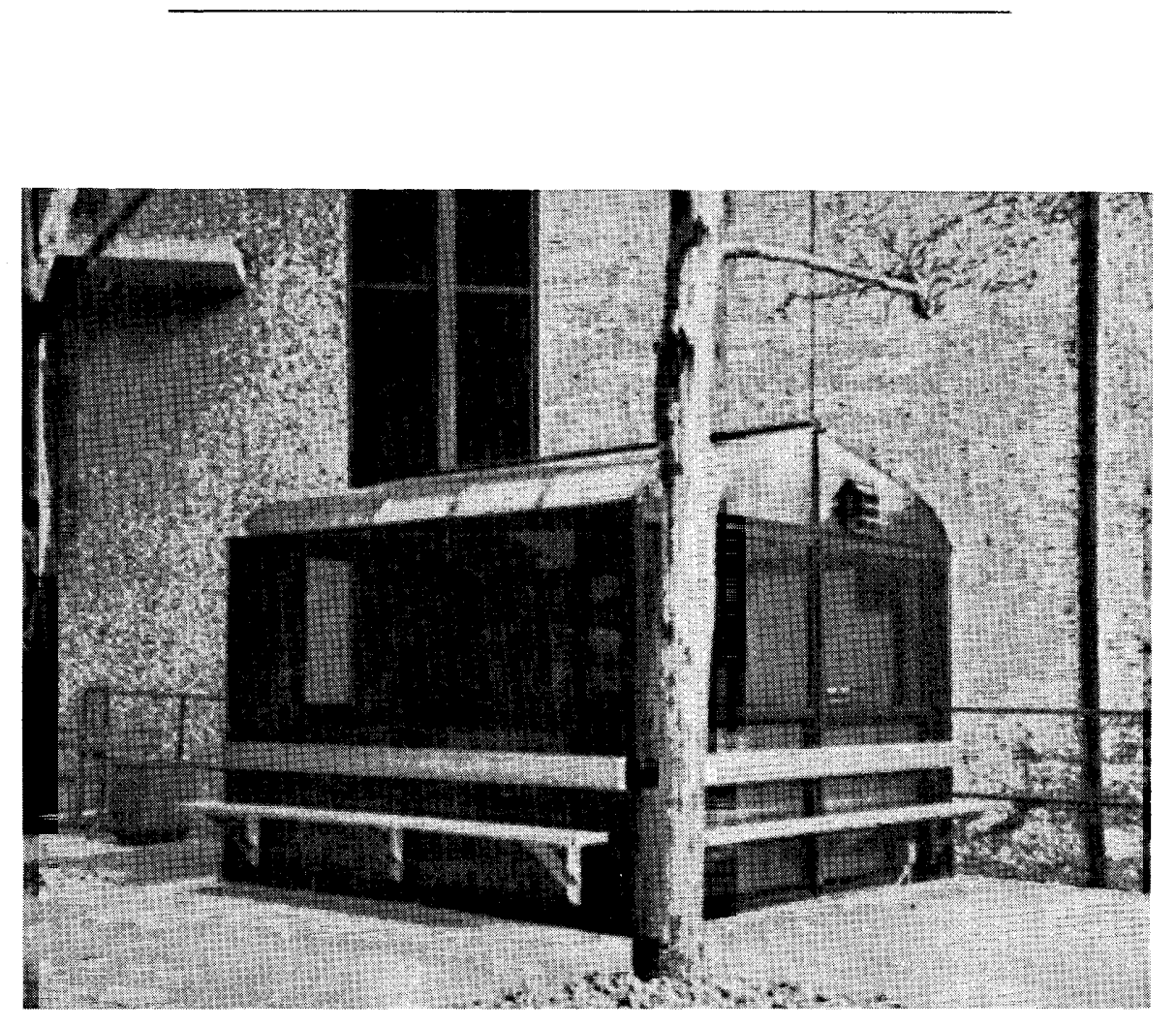

A smoking shelter outside a hospital in Columbus, Ohio, USA. Source: Duo-Gard Industries, Inc; Westland, Michigan, USA. 